\title{
Somos jardineros: Una propuesta lúdica para la enseñanza de las ciencias en Educación Infantil
}

\author{
Rosa Jiménez Espinoza, Alicia Fernández Oliveras y María Luisa Oliveras. Universidad de \\ Granada \\ Recepción: 12 de abril de 2015 | Revisión: 30 de mayo de 2015 | Aceptación/Publicación: 24 de julio de 2015 \\ Correspondencia: rosaj2491@gmail.com | alilia@ugr.es | oliveras@ugr.es | http://hdl.handle.net/10481/37115
}

Resumen: En este trabajo nos hemos propuesto diseñar y plantear una dinámica lúdica con la que se desarrolle principalmente el área de la etapa de Educación Infantil relacionada con el conocimiento del entorno, pero sin olvidar las demás. La propuesta puede llevarse a cabo tanto en el exterior como en interior, o combinando ambos tipos de espacios, y sus características se muestran en dos fichas que podrían incorporarse al archivo de cualquier centro de educación no formal o de ocio educativo, en el que se pretendiera desarrollar. Entre los fundamentos teóricos de la dinámica lúdica planteada se encuentran algunas de las ideas de Rousseau sobre la educación, como el aprendizaje mediante la experimentación.

Palabras clave: Didáctica de las Ciencias Experimentales | Formación del Profesorado | Educación Infantil | Juegos Educativos

WE ARE GARDENERS: A PLAYFUL APPROACH TO SCIENCE TEACHING IN EARLY CHILDHOOD EDUCATION

\begin{abstract}
In this paper we intend to design and plan a playful dynamic to mainly develop the area of kindergarten education related to environmental knowledge, but without forgetting the others. The proposal can be carried out either inside or outside, or combining both spaces. Its characteristics are shown on two index cards that could be incorporated into the file of any centre of non-formal education or educational play. Among the theoretical foundation of this playful dynamic are some of Rousseau's ideas on education, such as learning through experimentation.
\end{abstract}

Keywords: Science Education | Early Childhood Education | Teacher Training | Educational Games

\section{Introducción}

Como se recoge en R.D. 1630/2006 de 29 de Diciembre (BOE n ${ }^{\circ} 4$ de 4 de Enero de 2007) los métodos de trabajo para el segundo ciclo de Educación Infantil han de ser las experiencias, las actividades y el juego.

En este trabajo nos hemos propuesto diseñar y plantear una dinámica lúdica con la que se desarrolle principalmente el segundo área de dicha etapa educativa: conocimiento del entorno, pero sin olvidar las otras dos. Respecto al aérea lenguajes: comunicación y representación, en la dinámica será de gran importancia que se cree un intercambio verbal entre los miembros del grupo, dando lugar a un juego cooperativo. $Y$ el bloque juego y movimiento del área conocimiento de sí mismo y autonomía personal adquirirá un papel crucial en esta propuesta.

Con una metodología de enseñanza-aprendizaje basada en el juego, se pretende evitar que los niños adquieran ideas científicas erróneas e, incluso, si ya las poseen, que los corrijan, intentando que durante el juego se despierte en ellos más interés por saber e indagar acerca de las ciencias experimentales. Esta propuesta está en consonancia con las concepciones de futuros maestros de educación, relacionadas con el juego y la educación científica infantil (Fernández-Oliveras y Oliveras, 2014b, 2015).

La temática que subyace en el juego propuesto son las plantas y, en particular, los aspectos relacionados con el proceso por el cual estas crecen las a partir de la siembra de semillas. Entre los fundamentos teóricos de la propuesta se encuentran algunas de las ideas de Rousseau (1985) sobre la educación, como el aprendizaje 
mediante la experimentación. Los aspectos más relevantes de la dinámica lúdica planteada se indican en dos fichas que podrían incorporarse al archivo de cualquier centro de educación no formal o de ocio educativo, en el que se pretendiera llevar a cabo esta propuesta. Los modelos de las fichas empleadas forman parte del material de una asignatura optativa del Grado en Maestro de Educación Infantil de la Universidad de Granada (Fernández-Oliveras y Oliveras, 2014a).

\section{DISEÑO Y ELABORACIÓN DEL JUEGO}

La propuesta se pensó como una variante de juego de mesa compuesta por varios sub-juegos relacionados con el objetivo final: plantar una semilla. Para articular la dinámica, se diseño un tablero con cinco pétalos, cada uno asociado a un subtema (juego del agua, del sol, de la tierra, de las herramientas, de las semillas y juego del sol). Para el diseño, se decidió emplear materiales que se preveían resistentes para niños de educación infantil.

La elaboración del juego fue artesanal y requirió varios días. En primer lugar se elaboró una lista con todo el material que había que adquirir para la fabricación del juego, para ello se utilizó; material de bricolaje, material escolar, material reciclado, así como otros "materiales naturales", de origen orgánico e inorgánico (Tabla 1).

Tabla 1. Material necesario para la elaboración del juego

\begin{tabular}{|l|l|l|l|}
\hline Material de bricolaje & Material escolar & Material reciclado & Materiales naturales \\
\hline Sierra de calar & Tijeras & Botellas de agua & Agua \\
Bisagras & Cutter & Restos de & Tierra de plantar \\
Bridas & Folios de colores & láminas de & Semillas \\
Lija & Cartulinas de colores & madera & \\
& Láminas de goma "eva" & Caja de zapatos & \\
& Pegamento de barra & Vasos de plástico & \\
& Cola blanca & Recipientes de & \\
& Rotuladores & corcho & \\
& Lápiz & & \\
& Goma & & \\
& Regla & & \\
\hline
\end{tabular}

Se comenzó por las tareas de bricolaje. Lo primero fue dibujar en las láminas el diseño de lo que se quería realizar y cortar las láminas de madera con la sierra de calar. El siguiente paso fue lijar las piezas y, finalmente, pintarlas. Este fue el proceso seguido para elaborar el juego del agua.

El tablero se decoró cortando y pegando folios de colores, imágenes impresas en papel y flechas de "goma eva" que indican el sentido del juego. Para la elaboración de las fichas y tarjetas, se emplearon también imágenes que fueron imprimidas, recortadas y posteriormente pegadas en cartulina.

Seguidamente se culminaron los detalles del juego de las herramientas representado en la (poner la masilla para pegar por detrás de las tarjetas de herramientas y escribir el título con rotulador en el cartón) y la elaboración del juego de las semillas, que consistió en recortar la imagen impresa en 12 partes iguales, pegar con cola cada una de ella en los palos depresores y escribir el número correspondiente.

A continuación se elaboró el juego de la tierra, cuya fabricación consistió en hacer un agujero en la tapa, decorarla con goma "eva". Después llenarla de tierra y esconder los recipientes con las imágenes dentro. Y para la elaboración del juego de la tierra, se 
recortaron 3 piezas de goma "eva" con forma de sol, se escribió en cada una de ellas una pregunta previamente elaborada y en los tacos de madera se escribieron 4 opciones de respuesta.

Finalmente, se forraron con plástico todas las tarjetas, fichas y el tablero, con el objetivo de que el juego sea más resistente y, por lo tanto, dure más tiempo. Por último, se metieron en una caja de tamaño pequeño las pegatinas, tarjetas y fichas, para llevar el juego a clase e implementarlo.

La última parte del juego, que es la de plantar, la única preparación que necesita es llevar el material (1 caja de corcho, 1 saco de tierra, semillas y guantes), para realizar la actividad en el momento de la implementación. La dinámica puede llevarse a cabo tanto en el exterior como en interior, o combinando ambos tipos de espacios.

\section{FICHAS TÉCNICA Y DIDÁCTICA DEL JUEGO}

En las Tablas 2 y 3 se indican los aspectos más relevantes de la dinámica lúdica propuesta. Estas dos fichas se podrían incorporar al archivo de cualquier centro de educación no formal o de ocio educativo, en el que se pretendiera desarrollar esta propuesta.

Tabla 2. Ficha técnica del juego "Somos jardineros"

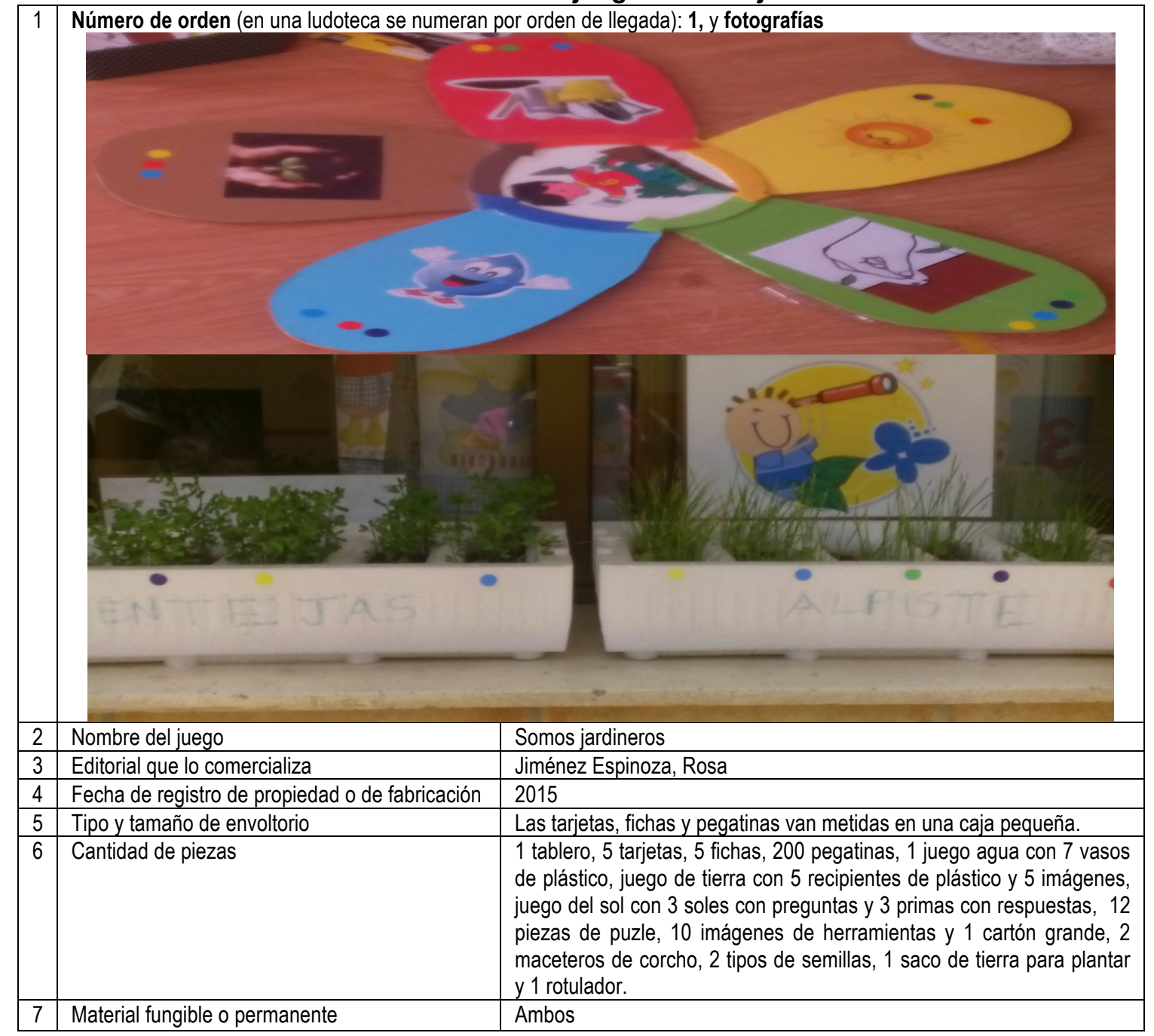


Tabla 2. Ficha didáctica del juego "Somos jardineros"

\begin{tabular}{|c|c|}
\hline Nombre del juego & Somos Jardineros \\
\hline $\begin{array}{l}\text { Piezas y material: descripción y } \\
\text { ccualidades intrínsecas (forma, color...) }\end{array}$ & $\begin{array}{l}\text { Tablero con forma de flor, } 5 \text { fichas con forma de flor, } 5 \text { tarjetas cada una con una imagen del tablero, } \\
\text { dos jardineras, tierra para cultivar, semillas de lentejas y alpiste, guantes, agua y pegatinas de } 5 \\
\text { colores. } \\
\text { Juego del agua: tablero vertical con dos botellas de agua y } 3 \text { vasos de plástico de un litro y cuatro de } \\
\text { cuarto de litro. } \\
\text { Juego de la tierra: caja con un agujero llena de tierra y } 5 \text { huevos con una imagen dentro. } \\
\text { Juego de las semillas: } 12 \text { piezas que forman un puzle y numeradas del } 1 \text { al } 12 \text {. } \\
\text { Juego del sol: } 3 \text { soles de "goma eva" con una pregunta cada uno y } 3 \text { piezas con las posibles } \\
\text { respuestas. } \\
\text { Juego de las herramientas: un panel y } 10 \text { tarjetas de herramientas. }\end{array}$ \\
\hline Lugar de fabricación & Granada \\
\hline Homologación & No \\
\hline Material del que están hechas las piezas & $\begin{array}{l}\text { El tablero y el juego del agua están hechos de unas láminas de madera de } 3 \mathrm{~mm} \text { de espesor. Para } \\
\text { este segundo se ha utilizado también vasos de plástico de un solo uso. } \\
\text { La caja del juego de la tierra está hecha de cartón, y el tablero del juego de las herramientas también. } \\
\text { El puzle de la semilla es de depresores de madera. } \\
\text { Para el juego del sol se han utilizado materiales de goma eva y tres tacos de madera de bastante } \\
\text { grosor. } \\
\text { Los maceteros son de corcho. } \\
\text { También se han utilizado materiales naturales como es el agua y la tierra. }\end{array}$ \\
\hline $\begin{array}{l}\text { Cualidades relativas de las piezas: } \\
\text { tamaños, texturas, volumen }\end{array}$ & $\begin{array}{l}\text { Se alternan texturas suaves y menos suaves, como son la de la "goma eva" y la madera. También hay } \\
\text { textura arenosa. }\end{array}$ \\
\hline Dinámica del juego y reglas: explicación & 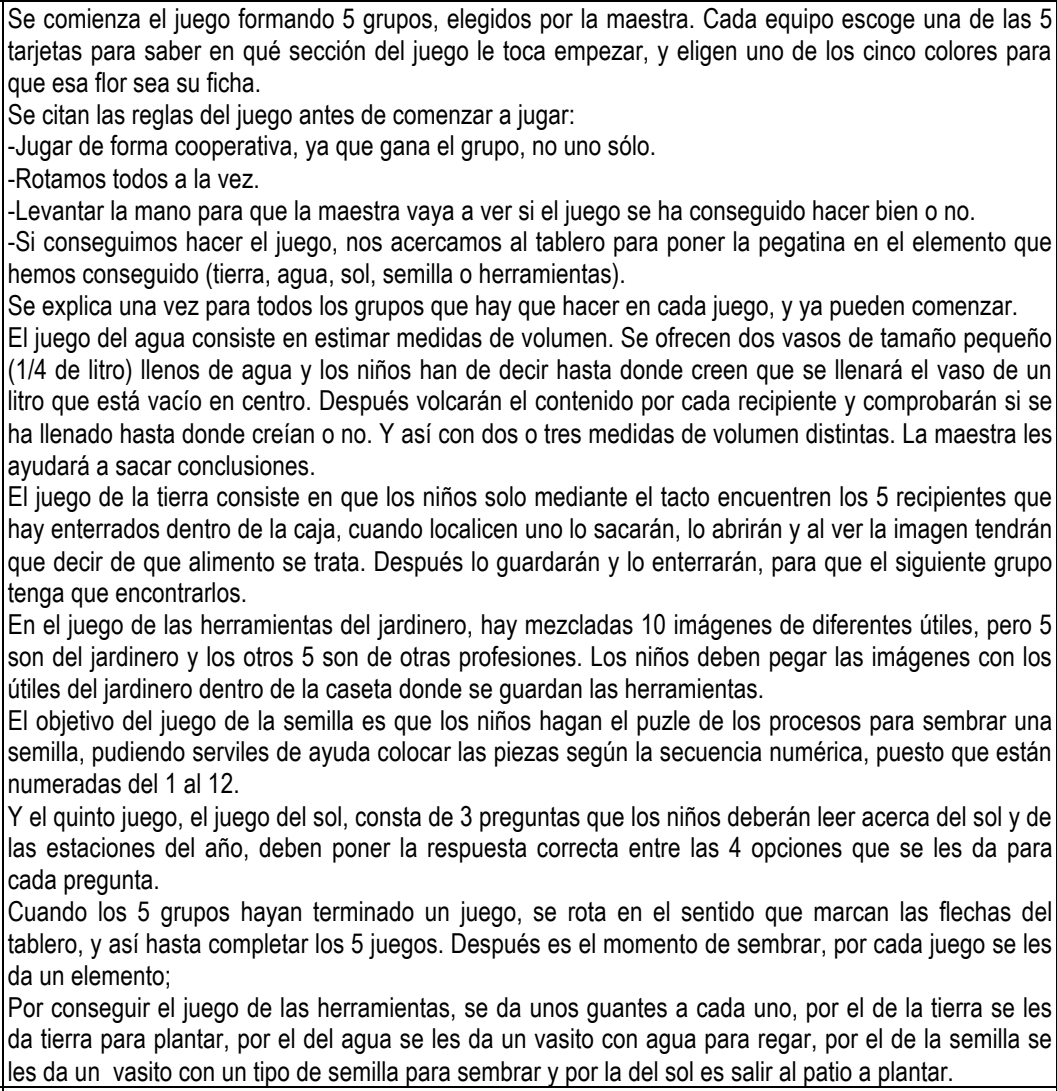 \\
\hline $\begin{array}{l}\text { Peligrosidad/riesgos (en las piezas o en } \\
\text { su uso con determinadas reglas) }\end{array}$ & El único riesgo puede ser la ingesta de tierra. \\
\hline Tiempo de preparación & 5 minutos \\
\hline Duración[corta/media/larga] & Larga, aproximadamente hora y media. \\
\hline $\mathrm{N}^{0}$ de jugadores & $1-25$ jugadores \\
\hline Edad preferente de los jugadores & 5 años \\
\hline De uso en interior/exterior & Ambos \\
\hline $\begin{array}{l}\text { Tipos de acciones de los jugadores } \\
\text { primordialmente (físicas, mentales, } \\
\text { ambas) }\end{array}$ & Físicas y mentales. \\
\hline Sentidos que se utilizan & Vista, oído, tacto. \\
\hline $\begin{array}{l}\text { Habilidades/capacidades o destrezas } \\
\text { que favorece (psicomotrices, } \\
\text { cognitivas...) }\end{array}$ & $\begin{array}{l}\text { Motricidad fina, el sentido del tacto y de la vista, la precisión, el razonamiento lógico, la organización } \\
\text { mental }\end{array}$ \\
\hline Objetivos propios del juego & $\begin{array}{l}\text { Identificar las herramientas que usa el jardinero. } \\
\text { Experimentar la medida del volumen con los recipientes y el agua. } \\
\text { Ordenar el puzle según el proceso de germinación de la planta. }\end{array}$ \\
\hline
\end{tabular}




\begin{tabular}{|c|c|}
\hline & $\begin{array}{l}\text { Reconocer el nombre de los vegetales que nacen bajo tierra. } \\
\text { Desarrollar el sentido del tacto. } \\
\text { Aprender características que relacionan la incidencia de la radiación del sol con cada estación del año. } \\
\text { Conocer los cinco elementos necesarios para la germinación. }\end{array}$ \\
\hline Coste económico & 30 euros \\
\hline Contenidos científicos y tecnológicos & $\begin{array}{l}\text {-Seriación. } \\
\text {-Clasificación. } \\
\text {-Secuencia numérica. } \\
\text {-Medida y estimación de volúmenes (capacidades). } \\
\text {-Partes de la planta (raíz, tallo, hojas, semilla, flor y fruto). } \\
\text {-Fases de germinación de una planta. } \\
\text {-Elementos que intervienen en el proceso de germinación. } \\
\text {-Características propias de la incidencia de la radiación del sol en cada estación del año. } \\
\text {-Conocimiento de los vegetales que crecen bajo tierra. } \\
\text {-Útiles y herramientas de jardinería. }\end{array}$ \\
\hline Autocorrección [Sí, de qué forma:... /No] & $\begin{array}{l}\text { El juego del agua tiene autocorrección, pues primero ellos hacen una aproximación de hasta donde se } \\
\text { llenará el vaso, y después comprueban si el agua ha llegado hasta la línea roja que hay señalada en el } \\
\text { vaso. } \\
\text { La segunda parte del juego, la de sembrar, también tiene autocorrección, pues la planta no crecerá si } \\
\text { falla alguno de los elementos o procesos. }\end{array}$ \\
\hline $\begin{array}{l}\text { Universalidad en sus reglas o } \\
\text { composición: puede ser comprendido } \\
\text { sin explicaciones [Sí/No] }\end{array}$ & $\begin{array}{l}\text { Algunas partes del juego sí, otras necesitan de una explicación. En una segunda vez ya no necesitan } \\
\text { explicación para jugar. }\end{array}$ \\
\hline $\begin{array}{l}\text { Fundamentación teórica (autores en los } \\
\text { que se basa) }\end{array}$ & Rousseau (1985) \\
\hline
\end{tabular}

\section{Reflexión final}

Desarrollando el trabajo resumido en este artículo se ha comprobado cómo puede planificarse una dinámica lúdica mediante la cual abordar contenidos de ciencias en la etapa infantil.

\section{Agradecimientos}

Al Secretariado de Innovación Docente del Vicerrectorado de Ordenación Académica y Profesorado de la Universidad de Granada (España), por conceder el Proyecto de Innovación Docente 2013-2016.

\section{Referencias}

Fernández-Oliveras, A. y Oliveras, M. L. (2014a). Playing for science and mathematics education: an experience for pre-service kindergarten teacher training. En Costa M. F. M., Pombo P., Dorrío B.V. (Eds.), Hands-on Science. Science Education with and for Society (180 -183). Braga: Hands-on Science Network.

Fernández-Oliveras, A. y Oliveras, M. L. (2014b). Pre-service kindergarten teachers' conceptions of play, science, mathematics, and education. Procedia - Social and Behavioral Sciences, 152, 856-861. DOI:10.1016/j.sbspro.2014.09.334.

Fernández-Oliveras, A. y Oliveras, M.L. (2015). Conceptions of science, mathematics, and education of prospective kindergarten teachers in a play-based training. International Journal on Advances in Education Research, 2(1), 37-48.

Real Decreto por el que se establecen las enseñanzas mínimas del segundo ciclo de Educación infantil (R.D. 1630/2006, 29 diciembre). Boletín Oficial del Estado, $n^{\circ}$ 4, 2007, 4 enero.

Rousseau, J. J. (1985). Emilio o de la Educación. Madrid: Edaf. 